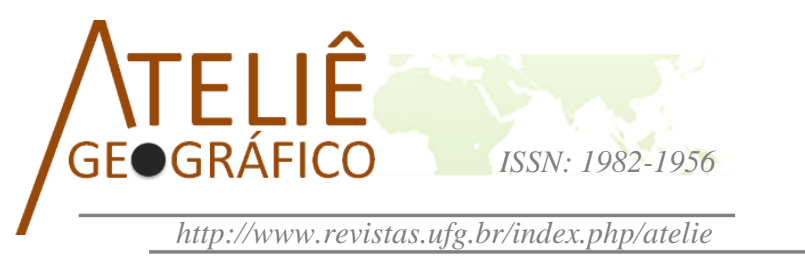

\title{
A salinização dos solos na concepção da comunidade quilombola de Cupira - Santa Maria da Boa Vista - Pernambuco
}

\author{
The salinity of the soils in the conception of the quilombola \\ community of Cupira - Santa Maria da Boa vista - \\ Pernambuco
}

\begin{abstract}
La salinización de los suelos en la concepción de la comunidad quilombola de Cupira - Santa Maria de Boa Vista-Pernambuco
\end{abstract}

Francelita Coelho Castro

Universidade do Estado da Bahia francelitacastro@gmail.com

Antonio Marcos dos santos Universidade de Pernambuco geo_fisica@yahoo.com.br

Jairton Fraga Araújo

Universidade do Estado da Bahia

jairtonfraga@bol.com.br

\begin{abstract}
Resumo
O presente estudo buscou analisar a inter-relação entre os conhecimentos práticos dos agricultores da comunidade quilombola de Cupira, semiárido do estado de Pernambuco, com o processo de salinização dos solos. Para desenvolvimento desse estudo, utilizou-se como base metodológica, a etnopedologia, elementos da cartografia social e as análises químicas das amostras de solo, coletadas sobre indicação dos agricultores. Os resultados indicam que a maioria dos agricultores reconhecem com facilidade, a ocorrência do processo de salinização, assim como, os impactos sobre a estrutura dos solos na produção agrícola. Conclui-se que os agricultores apresentam conhecimentos práticos para reconhecer o processo de salinização e, também, as práticas que colaboram para o desenvolvimento do acúmulo de sais, no entanto, verifica-se a necessidade da soma do conhecimento
\end{abstract}


técnico-científico e do auxílio de políticas públicas para resolver, e evitar os problemas oriundos da salinização.

Palavras-Chave: Degradação dos solos; Etnopedologia; Comunidade tradicional.

\begin{abstract}
Asbract
The present study sought to analyze the interrelation between the practical knowledges of the farmers of the quilombola community of Cupira, semiarid of the state of Pernambuco, with the process of salinity of the soils. For the development of this study, the ethnopedology, elements of social cartography and the chemical analysis of soil samples, collected on farmers' indication, were used as a methodological basis. The results indicate that most farmers recognize easily the occurrence of the salinity process, as well, as impacts on soil structure in the agricultural production. It is concluded that the farmers present practical knowledges to recognize the process of salinity and also, the practices that collaborate for the development of the accumulation of salts, nevertheless, it was verified the need for the sum of technical scientific knowledge and the aid of public policies to solve and avoid problems arising from salinity.
\end{abstract}

Keywords: Degradation of the soils; Ethnopedology; Traditional community.

\begin{abstract}
Resumen
El presente estudio buscó analizar la interrelación entre los conocimientos prácticos de los agricultores de la comunidad Quilombola de Cupira, semiárido del estado de Pernambuco con el proceso de salinización de los suelos. Para el desarrollo de este estudio se utilizó como base metodológica la etnopedología, elementos de la cartografía social y análisis químicos de muestras de suelo recogidas sobre indicación de los agricultores. Los resultados indican que la mayoría de los agricultores reconocen con facilidad la ocurrencia del proceso de salinización, así como los impactos sobre la estructura de los suelos y en la producción agrícola. Se concluye que los agricultores presentan conocimientos prácticos para reconocer el proceso de salinización y también las prácticas que colaboran para el desarrollo de la acumulación de sales, sin embargo, se verifica la necesidad de la suma del conocimiento técnico-científico y la ayuda de políticas públicas para la resolución, así como, evitar los problemas derivados de la salinización.
\end{abstract}

Palabras claves: Degradación del suelo; etnoedafología; Comunidad tradicional.

\title{
Introdução
}

Dentre as diversas formas de degradação de áreas de produção agrícola está o processo de salinização dos solos definido como o acúmulo de sais solúveis nas camadas superficiais dos solos onde localizam o sistema radicular das plantas (PENG et al., 2016). A salinização é responsável pela redução da produção agrícola em muitos países, incluindo o Brasil (RIBEIRO, 2010).

No semiárido brasileiro, os casos mais contundentes de salinização ocorrem na região semiárida tendo como principal agente indutor as atividades humanas. Estima-se que 25\% dos solos irrigados apresentam problemas de salinização (PEDROTTI et. al., 2015).

Entender como os agricultores das áreas atingidas lidam com esse problema é um grande desafio, visto que, boa parte dos estudos sempre utilizam os métodos de pesquisas tradicionais, onde os agricultores aparecem como agentes secundários na 
tomada das informações. Na tentativa de equalizar e levar em consideração os conhecimentos práticos e culturais dos agricultores sobre os problemas inerentes à degradação dos solos, desenvolveu-se a etnopedologia.

A etnopedologia faz parte da etnoecologia estruturada a partir da combinação entre conhecimentos desenvolvidos pelas ciências sociais, a exemplo da geografia e da antropologia, e pelas ciências naturais destacando a agronomia, as geociências, entre outras (BARRERA-BASSOLS \& ZINCK, 2003; ARAÚJO et al., 2013). Nos estudos que envolvem esse método os conhecimentos culturais "populares", as práticas não científicas de manejo dos solos e a visão de mundo da comunidade trabalhada devem ser consideradas (WAHLHÜTTER, VOGL \& EBERRHART, 2016).

Esse campo do conhecimento teve, e continua tendo importância no desenvolvimento e aprimoramento de manejos agrícolas, assim como, contribui para diversas práticas científicas empregadas atualmente nos estudos dos solos. Cita-se como exemplo o primeiro sistema de classificação de solos registrado no livro chinês Yugong, datado de aproximadamente 2500 anos Antes de Cristo (NATH, LAL \& DAS, 2015).

Para Nezomba et al. (2017) a prática da etnopedologia parte da premissa de que os indivíduos que compõe uma comunidade e que trabalham no manejo dos solos a muito tempo estão bem informados sobre os indicadores de produtividade de suas terras. Lima et al. (2011) destaca que a percepção dos agentes das comunidades direcionadas às práticas agrícolas colaboram no processo de avaliação da degradação dos solos. Elemento importante que aliado aos conhecimentos técnico-científicos ajudam na eficácia da resolução dos problemas ambientais inerentes aos manejos agrícolas.

Outro método que vem sendo utilizado como suporte para os estudos que envolvem os conhecimentos tradicionais dos agricultores sobre manejo, degradação dos solos, afirmações de identidades coletivas, reconhecimento de direitos étnicos, conservação de práticas e culturas ancestrais e demarcação de territórios é a cartografia social. Esse método colabora na produção de mapeamentos que tem como fonte de informações os agentes sociais que habitam comunidades tradicionais para representação de suas realidades, com ajuda de outros agentes que compartilham a base técnica e infra estrutural para a elaboração dos mapas (BARGAS \& CARDOSO, 2015; SANTOS, 2016).

Segundo Gorayeb, Meireles e Silva (2015) a cartografia social é uma linha de pesquisa da Ciência Cartográfica que privilegia o conhecimento popular, simbólico e cultural, como meio de produzir mapeamentos de territórios tradicionais, étnicos, sagrados e coletivos e por isso é de suma importância para a defesa e registro dos conhecimentos e territórios tradicionais.

Na comunidade Quilombola de Cupira, município de Santa Maria da Boa Vista, estado de Pernambuco, o processo de salinização é evidente principalmente em áreas sobre agricultura irrigada, associada a solos susceptíveis à salinização (CASTRO, ARAÚJO \& SANTOS, 2019). Diante do que foi apresentado anteriormente, dois questionamentos guiam o desenvolvimento deste artigo: o primeiro, como os 
agricultores da citada comunidade tradicional percebem e trabalham com a problemática da salinização dos solos? E o outro, será que a percepção desses agricultores estão interligadas com os conhecimentos técnico-científicos avaliados em laboratório?

É na tentativa de responder tais questionamentos que o presente artigo tem como objetivo analisar a inter-relação entre os conhecimentos práticos pelos agricultores da comunidade Quilombola de Cupira com o processo de salinização dos solos locais. Para isso, será empregado as proposições da etnopedologia.

\section{Materiais e Métodos}

\section{Localização e Caracterização da Área de Estudo}

A comunidade quilombola de Cupira está localizada à cerca de $14 \mathrm{~km}$ da cidade de Santa Maria da Boa Vista, semiárido do estado de Pernambuco (Figura 01) nas margens do rio São Francisco. Tal comunidade foi certificada em 2008 pela Fundação Cultural Palmares. Com cerca de 220 famílias, a comunidade possui como principais atividades de subsistência a agricultura irrigada, o artesanato e a pesca, todas realizadas em regime familiar.

A história da comunidade foi relatada pelo senhor João Aposto um dos mais antigos moradores. Segundo ele, a comunidade se chamava Estreito, devido à extensão de terra ser pouca entre a serra e o Rio São Francisco. O nome de Cupira veio mais tarde por causa da marcante presença de seu Manoel Cupira, pescador do Velho Chico e que gostava muito de coletar o mel de abelha cupira, motivo pelo qual recebeu o cognome e deixou registrado na história da comunidade.
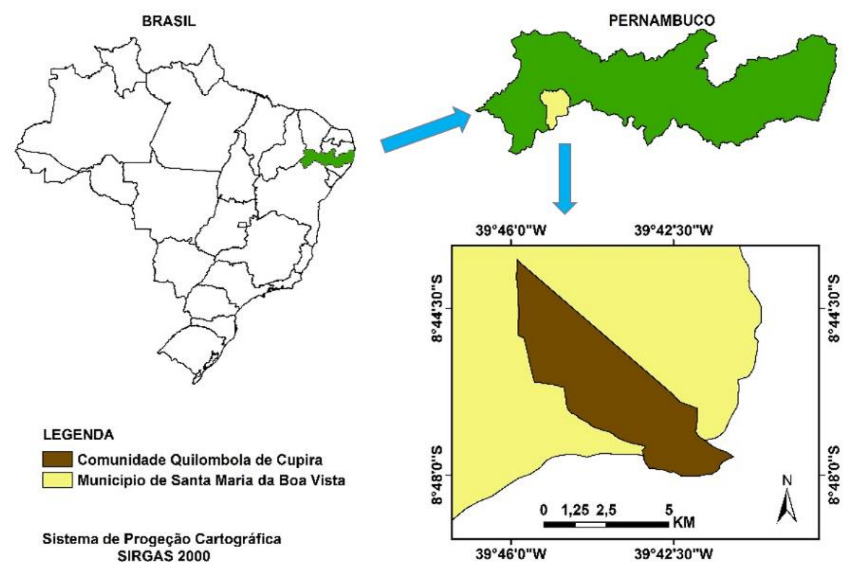

Figura 01: Localização da comunidade quilombola do Cupira - Santa Maria da Boa Vista - Pernambuco.

Fonte: elaborada pelos autores (2018). 
A Associação Quilombola dos Agricultores Familiares e Pescadores do Território de Cupira (AQAFPTC), fundada em 14 de maio de 2001, trabalha para defender o território quilombola, respeitar e fazer respeitar a autonomia e autodeterminação dos quilombolas como forma de organização política e social própria valorizando sua identidade cultural de comunidade negra rural, ademais, vem realizando ações de resgate cultural como grupo de São Gonzalo; grupo Ydandiê e o Samba de Roda Penerou.

\section{Procedimentos Metodológicos}

A primeira etapa de trabalho foi à coleta de informação em campo para confecção do mapa das áreas salinizadas. Esse mapeamento foi realizado de acordo com a metodologia da cartografia social. Para isso, realizou-se visita a comunidade para reunião com seus representantes com objetivo de esclarecer que as entrevistas deveriam ser realizadas com os agricultores mais experientes no manejo da agricultura irrigada realizada naquele território. Após a indicação dos agricultores pelas líderes deu-se início as entrevistas.

As entrevistas, semiestruturadas, elaboradas a partir dos princípios da etnopedologia, ocorreram na área de produção de cada entrevistado e foram realizadas individualmente. Nesse momento o agricultor indicava o local de sua área de produção, que segundo eles estão salinizada de acordo com os conhecimentos desenvolvidos na inter-relação dele com o ambiente e com os indicadores que os mesmos utilizam para tal definição. Ao todo foram entrevistados 14 agricultores.

Nas áreas indicadas como salinizadas pelos agricultores foram construídos 4 perfis de $30 \mathrm{~cm}$, sendo coletadas amostras de solos, as quais foram homogeneizadas em baldes plásticos indicando a representatividade do local e, em seguida, enviadas para laboratório. Esse procedimento está baseado no Manual de Procedimentos de Coleta de Amostras elaborado por Filizola, Gomes e Souza (2006). Além das coletas, cada área indicada foi catalogada através de pares de coordenadas geográficas via aparelho receptor de GPS (Sistema de Posicionamento Global). Informações utilizadas na confecção do mapa posteriormente em laboratório.

De posse das coletas de campo, os mesmos foram processados em laboratório, constituindo assim, a segunda etapa de estudo. Todas as amostras de solos foram submetidas a análises químicas sendo realizados testes de $\mathrm{pH}$ (potencial Hidrogeniônico), CE (Condutividade Elétrica) e PST (Porcentagem de Sódio Trocável). Todo procedimento laboratorial foi baseado no Manual de Métodos de Análise de Solos (EMBRAPA, 2011). Posteriormente, as análises químicas foram correlacionadas com as respostas dos agricultores.

Por último foi confeccionada a carta das áreas salinizadas da comunidade. Levando em consideração as informações dos agricultores com os mecanismos da cartografia social. A Cartografia Social é um processo protagonizado pelas próprias comunidades, ou seja, elas realizam o mapeamento fornecendo os dados (ALMEIDA, 
2006) e os pesquisadores, participam do processo da construção dos mapas oferecendo suporte técnico-instrumental.

Os pontos das áreas indicadas como salinizadas registradas em campo através do aparelho receptor de GPS foram descarregados no software Arcgis, o qual foi utilizado para confecção do mapa. Em seguida foram adicionados ao mapa os resultados das análises químicas.

Para legalização do uso das informações coletadas em campo, o projeto que deu origem a esse artigo foi aprovado pelo comitê de ética da Universidade do Estado da Bahia, parecer 2.007.840. Nos primeiros encontros com os representantes da comunidade e com os agricultores, foram esclarecidas as dúvidas dos participantes da pesquisa, sobre o projeto e o uso das informações que seriam coletadas. Posteriormente, todos assinaram o TCLE (Termo de Consentimento Livre e Esclarecido).

\section{Resultados e discussão}

A figura 02 apresenta os pontos das áreas salinizadas identificadas pelos agricultores da comunidade Quilombola de Cupira junto com os pontos das amostras submetidas as análises químicas dos solos.

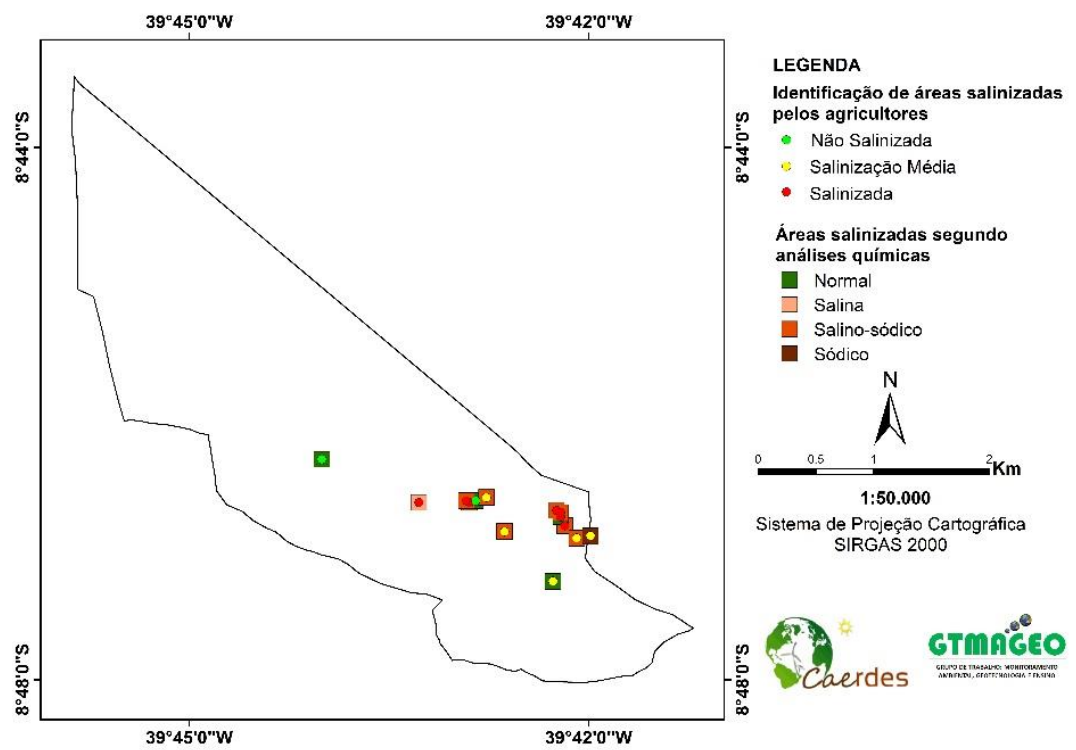

Figura 02: Carta das áreas salinizadas da Comunidade Quilombola de Cupira em Santa Maria da Boa Vista - PE.

Fonte: elaborado pelos autores (2017). 
De acordo com o apresentado na figura 02, as análises químicas (quadro 01) correlacionaram em $72,22 \%$ com as áreas indicadas pelos agricultores como salinizadas. Esse comparativo demonstra que as práticas e conhecimentos diários desses agricultores contribuem para que os mesmos consigam identificar com facilidade a presença de sais nos solos, assim como, correlacionarem sua produção com os problemas ligados à presença de sais.

Quadro 01: classificação das amostras de solo coletadas nas áreas indicadas pelos os agricultores como salinizadas.

\begin{tabular}{|c|c|c|c|c|}
\hline $\begin{array}{c}\text { Propriedade dos } \\
\text { agricultores }\end{array}$ & $\mathbf{p H}$ & $\mathbf{C E}\left(\mathbf{d s ~ m}^{\mathbf{- 1}}\right)$ & PST (\%) & $\begin{array}{c}\text { Classificação das } \\
\text { amostras }\end{array}$ \\
\hline Agricultor 1 & 6,46 & 6,81 & 49,08 & Salino-sódico \\
\hline Agricultor 2 & 6,64 & 58,64 & 1,50 & Salino \\
\hline Agricultor 3 & 6,32 & 1,07 & 2,47 & Normal \\
\hline Agricultor 4 & 6,67 & 0,9 & 0,36 & Normal \\
\hline Agricultor 5 & 5,79 & 8,29 & 35,73 & Salino-sódico \\
\hline Agricultor 6 & 4,9 & 3,89 & 25,10 & Salino-sódico \\
\hline Agricultor 7 & 5,88 & 3,69 & 35,77 & Salino-sódico \\
\hline Agricultor 8 & 6,06 & 1,1 & 22,71 & Sódico \\
\hline Agricultor 9 & 5,22 & 29,84 & 58,24 & Salino-sódico \\
\hline Agricultor 10 & 5,88 & 0,87 & 1,80 & Normal \\
\hline Agricultor 11 & 5,36 & 0,47 & 0,75 & Normal \\
\hline Agricultor 12 & 6,76 & 3,02 & 17,97 & Salino-sódico \\
\hline Agricultor 13 & 4,47 & 4,37 & 53,14 & Salino-sódico \\
\hline Agricultor 14 & 6,31 & 11,43 & 22,20 & Salino-sódico \\
\hline
\end{tabular}

Fonte: elaborado pelos autores (2018).

A resposta do que foi comentado anteriormente, pode ser explorado através das respostas que os agricultores apresentaram sobre o conceito de salinização e suas consequências.

Treze agricultores apresentaram explicações do que seria a salinização dos solos. As respostas que mais convergiram destacam que a salinização é o excesso de sais nos solos, o que prejudicam as plantas e a produção agrícola. Para a maioria desses agricultores a irrigação mal desenvolvida contribui para concentração de sais sobre os solos.

Diante dos relatos dos agricultores constatam-se que eles já perceberam que o processo de salinização dos solos prejudicam as plantas, a capacidade de produção e tendem a diminuir seus ganhos econômicos caso o problema se agrave. Consequência destacada por Gonçalves, Martins e Ramos (2015), os quais destacam que os elevados níveis de sais nos solos e na solução do mesmo acarretam prejuízos na produção agrícola. 
Outro aspecto verificado foi que os agricultores entrevistados sabem da importância do sistema de drenagem e, que a prática de irrigar por sulco contribui para o acúmulo de sais no solo. Segundo Pedrotti et al. (2015) a prática da irrigação sem um manejo adequado e com o sistema de drenagem deficiente contribuem para que o processo de salinização seja acelerado, podendo atingir níveis prejudiciais à maioria das culturas em um espaço de tempo considerado curto.

Foi solicitado aos agricultores que listassem características das transformações que surgiram na área de produção que fosse consideradas consequências da salinização dos solos. Várias características foram apresentadas por eles, dentre elas estão: "Na terra aparecem manchas brancas ou que parece gordura; nas plantas, elas não carregam bem e as folhas são amareladas, amarelam até secar" (Agricultor 3). Outro relato indica que: "A terra fica com textura crespa, com manchas brancas e nas plantas, o cacho da banana não cresce e o pé torra antes de crescer" (Agricultor 4).

Observa-se nos relatos desses agricultores características nítidas do processo de salinização. As manchas brancas no solo representam o grau avançado da concentração de sais nas camadas superficiais dos solos presentes em alguns pontos da comunidade (Figura 03A). Outras duas observações são as manchas que, segundo eles parecem gorduras sobre os solos, além da textura que eles classificam como crespa.

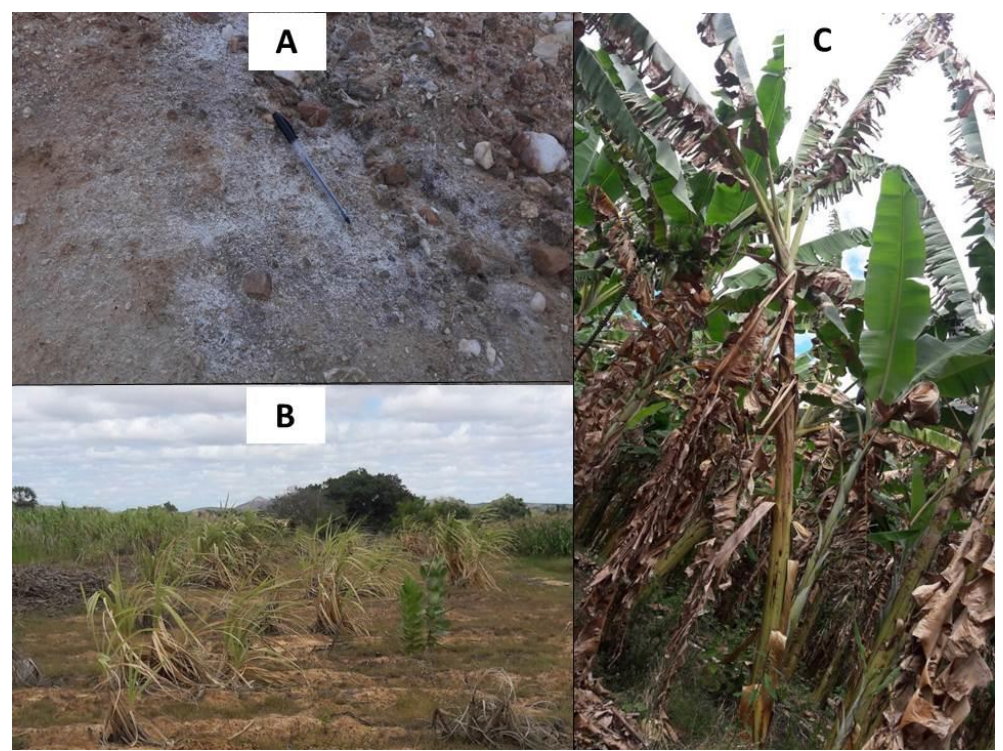

Figura 03: (A) manchas brancas caracterizando presença de sais no solo; (B) plantio de cana-de- açúcar (Saccharum officinarum) prejudicado pela presença de sais no solo; (C) cultivo de banana (Musa spp.) com queimaduras devido à presença de sais no solo.

Fonte: elaborado pelos autores (2018). 
De acordo com Brady e Weil (2013) a elevada concentração de sódio no solo pode causar a degradação de estruturas dos solos e a perda da macroporosidade, causando assim, restrição no movimento da água e do ar no solo. Característica que corresponde aos resultados das análises químicas de boa parte dos solos irrigados na comunidade classificados como salino-sódico (Quadro 01). Isso justifica a restrição à capacidade de infiltração dos solos apresentando a aparência de "gordura sobre a terra" (Agricultor 3) indício de modificações da estrutura física dos solos.

Os demais indicadores apresentados pelos entrevistados destacaram a aparência úmida dos solos e as folhas secas, a exemplo do relato do Agricultor 13, em que "A terra aparenta molhada e as plantas com as folhas secas como se tivesse com sede”.

Quanto aos impactos visíveis entre os efeitos da salinização dos solos e a produção agrícola (Quadro 02) 13 agricultores responderam que a presença de sais nos solos apresentam sinais em suas áreas de produção. Citaram como exemplo: as queimaduras nas bordas das folhas (Figura 3C); perda dos frutos; manchas brancas nos solos com aparência de umidade e folhas com cores amarelas.

O processo relatado anteriormente, pelos agricultores, pode ser originário da intoxicação das plantas pelo excesso de sais nos solos; pressão osmótica e perda de fertilidade dos solos. Degradação essa que impede o desenvolvimento adequado da maioria das plantas (HAMMECKER et al., 2012; SALVATI \& FERRARA, 2015; GONÇALVES, MARTINS \& RAMOS, 2015).

Quadro 02: respostas dos agricultores com relação ao processo de salinização dos solos na Comunidade Quilombola de Cupira - PE.

\begin{tabular}{|c|c|c|c|}
\hline $\begin{array}{c}\text { QUESTIONAMENTOS REALIZADOS AOS } \\
\text { AGRICULTORES }\end{array}$ & SIM & NÃO & $\begin{array}{c}\text { NÃO } \\
\text { RESPONDEU }\end{array}$ \\
\hline $\begin{array}{c}\text { Impactos visíveis entre os efeitos da salinização dos solos } \\
\text { e a produção agrícola }\end{array}$ & 13 & 1 & 0 \\
\hline $\begin{array}{c}\text { Apresenta perda de produtividade por causa da } \\
\text { salinização }\end{array}$ & 12 & 2 & 0 \\
\hline $\begin{array}{c}\text { A quantidade de água aplicada influencia para o } \\
\text { desenvolvimento do processo de salinização }\end{array}$ & 12 & 2 & 0 \\
\hline $\begin{array}{c}\text { Os adubos químicos contribuem para o processo de } \\
\text { salinização }\end{array}$ & 10 & 3 & 1 \\
\hline A irrigação por sulco prejudica os solo e as plantas & 9 & 4 & 0 \\
\hline Já realizou análises químicas do solo & 2 & 12 & 0 \\
\hline Recebe assistência técnica & 2 & 12 & 0 \\
\hline $\begin{array}{c}\text { Utiliza representatividade simbólica para determinar } \\
\text { alguma atividade de manejo }\end{array}$ & 3 & 11 & 0 \\
\hline $\begin{array}{c}\text { A salinização dos solos pode ser considerado um } \\
\text { problema grave para a produção agrícola }\end{array}$ & 14 & 0 & \\
\hline
\end{tabular}

Fonte: Elaborado pelos autores (2018).

Outra questão levantada foi à redução da produtividade causada pelo processo de salinização dos solos. A maioria (12 agricultores) responderam que em suas áreas ocorreram queda na produção. Apenas em duas propriedades ainda não apresentaram perdas nas produções. 
O agricultor 2 relata que: "Quase tudo que a gente planta não produz bem". $\mathrm{O}$ agricultor 5 destaca que: "Estão queimando as folhas e as plantas produzem mais pouco" (Figura 3C). O agricultor 9 acrescenta que: “(...) tem perda na colheita. O maracujá mesmo depois de grande, murcha e cai". Os demais relataram que parte da área apresentam mortes das plantas adultas e reduções na produção sobre as áreas que eles classificam como salinizadas.

A figura 3B apresenta uma das áreas indicadas pelos agricultores com problema de produção. Observa-se a presença de áreas abertas oriundas da morte de espécies vegetais plantadas. No caso da área indicada, o cultivo é de cana-de-açúcar (Saccharum officinarum). Os relatos dos agricultores apontam para características de áreas com níveis elevados de salinização prejudicando a produção e causando prejuízos ao agricultor. Sendo essas características reflexo de um solo classificado como salino-sódico (Quadro 1).

Outro ponto abordado foi à relação entre a quantidade das águas empregadas na irrigação local e a salinização dos solos. Para Ribeiro (2010) a ascensão dos sais por capilaridade é uma das principais causas da salinização dos solos. Para esse efeito ocorrer a água em excesso desce por efeito gravitacional até as camadas mais profundas e ao subir (efeito de capilaridade) a superfície a água evapora e os sais acumulam-se sobre a superfície.

A maioria dos agricultores acreditam que a quantidade de água aplicada influencia no desenvolvimento do processo de salinização dos solos. Pode-se destacar o relato do agricultor 2, que para ele "A água demais traz a salinização".

Porém, entre os 14 agricultores entrevistados dois acreditam no contrário. Para eles o excesso de água contribui para retirada dos sais dos solos. O agricultor 10 observou que a grande quantidade de água em sua propriedade está contribuindo na retirada dos sais dos solos ao dizer: "Quanto maior a quantidade de água mais retira os sais". O que contribui para a salinização dos solos na região semiárida é a taxa de evapotranspiração que supera a taxa de precipitação pluviométrica, assim, não ocorre a lixiviação dos sais presentes nos solos (PEDROTTI et al., 2015). A aplicação de grande quantidade de água pelo agricultor pode está colaborando no processo de lixiviação dos sais, caso o solo de sua área apresente boa drenagem natural.

Quando analisado os resultados das análises químicas, os dois agricultores que responderam que a quantidade de água não influencia na salinização, um deles possui sistema de irrigação por microaspersão e solo considerado normal, sem problemas com salinização, segundo as análises em laboratório. Já o segundo agricultor (agricultor 5) utiliza sistema de irrigação por sulco e apresenta um solo salino-sódico (Quadro1).

Quanto aos insumos agrícolas 10 agricultores concordam que a adubação química auxilia no processo de salinização dos solos. Segundo eles, existem alguns produtos utilizados que colaboram na salinização como relata o agricultor 3: "Uns influência mais do que outros, o pior é o tal do sulfato. Ele é o pior para a salinização". 
O agricultor 8, também, apontou as implicações da adubação no processo de salinização, segundo ele: “(...) tem muitos produtos que não tem e outros tem sal”.

Os demais entrevistados apontaram que os insumos (adubos químicos) não colaboram para salinização. Segundo o agricultor 1 os adubos não representam riscos à salinização, visto que, o problema encontra-se nos solos. Segundo Silva (2014), Shen et. al. (2016) e Chu et. al. (2017) a aplicação de adubação química sem planejamento pode contribuir inicialmente, para alta produtividade agrícola, porém com o passar do tempo irá colaborar com o processo de salinização dos solos.

O método de irrigação também foi investigado. A maioria dos agricultores utilizam a irrigação por sulcos. Ao serem questionados se esse método favorece a salinização dos solos, 9 agricultores apontaram positivamente e 4 comentaram que não há influência. Entre as opiniões que apontam a colaboração da irrigação por sulcos, o agricultor 9 destaca que: "O sulco prejudica porque empossa água nos locais mais baixos". Para uma pequena minoria, como o agricultor 3 , o problema de salinização não apresenta contribuição do método de irrigação. Segundo eles os principais problemas estão na qualidade das águas, adubações e sais presentes naturalmente nos solos.

Pesquisadores alertam que o método de irrigação através de sulcos possui sérias desvantagens devido ao acúmulo de sais provenientes da maior quantidade de água colocada no solo e consequentemente, um maior tempo de permanência da mesma (TESTEZLAF, 2017).

Quanto às experiências que os agricultores possuem no manejo das terras todos indicam que usam os conhecimentos passados de geração a geração. Isso aponta a importância cultural no manejo das terras na comunidade.

A assistência é outro desafio enfrentado pelos agricultores. Apenas dois proprietários receberam auxílios nos últimos anos, todas prestadas por funcionários dos estabelecimentos comerciais que fornecem insumos agrícolas. Resultado agravante diante dos fortes riscos de salinização dos solos da comunidade quilombola.

Outro aspecto analisado foi o uso de representações simbólicas e culturais no desenvolvimento das práticas agrícolas relacionadas à salinização dos solos. Apenas três agricultores responderam que fazem uso das representações e as respostas foram variadas. Para alguns, a fase da lua é importante para o crescimento e desenvolvimento dos frutos, assim como, para evitar pragas. Porém, nenhum associou as práticas à salinização dos solos.

Quanto à gravidade do processo de salinização dos solos, todos os agricultores consideram esse problema grave e que apresentam problemas à produção agrícola. Para essa resposta parte dos agricultores apresentaram problemas observados em suas práticas diárias como: redução da produção; endurecimento dos solos e áreas salinizadas sendo abandonadas.

O estado de gravidade dos solos salinizados é alto, visto que, as concentrações elevadas de sais proporcionam perda parcial ou, até total, da capacidade de produção das 
terras por causa das degradações implicadas nas propriedades químicas e físicas dos solos. Problema presente desde a capitação de água pelas plantas até a desagregação das partículas físicas reduzindo a taxa de infiltração no solo (BRADY \& WEIL, 2013; GKIOUGKIS et al., 2015).

\section{Considerações Finais}

Os agricultores da comunidade quilombola de Cupira definem o processo de salinização como um grave problema para a produção agrícola, compreendem na grande maioria que práticas como adubação química e irrigação por sulco contribuem para o acúmulo de sais.

Conclui-se que os conhecimentos dos agricultores corroboraram com relação as características apresentadas por eles, como indicadores das áreas salinizadas, a exemplo: das manchas brancas no solo; das plantas que não produzem bem e das folhas que ficam amareladas, o que demonstram que são características que segundo o conhecimento técnico-científico são causas dos sais em excesso nas áreas agrícolas.

O alerta vai para a falta de assistência técnica, que apesar dos bons resultados de reconhecimento do processo de salinização e das práticas responsáveis por prejudicar os solos, o conhecimento prático precisa ser somado com os conhecimentos técnicocientíficos e políticas públicas para resolução ou amenização dos problemas já causados pela salinização e para evitar o seu agravamento.

Para ciência geográfica o estudo abre um leque na discussão que envolve a salinização dos solos e sua relação com as comunidades tradicionais, sejam ela quilombola, ribeirinha, indígena, entre outras. Tema latente e ainda pouco explorado pelas bases conceituais dessa ciência.

\section{Referências}

ALMEIDA, A. W. B. Terras de quilombo, terras indígenas, "babaçuais livres", "castanhais do povo", faxinais e fundos de pasto: terras tradicionalmente ocupadas. Manaus: FUA, 2006.

ARAÚJO, A. L.; ALVES, A. G. C.; ROMERO, R. E.; FERREIRA, T. O. Etnopedologia: uma abordagem das etnociências sobre as relações entre as sociedades e os solos. Ciência Rural, v.43, n.5, p.854-860, 2013.

BARGAS, J. K. R; CARDOSO, L. F. C. Cartografia social e organização política das comunidades remanescentes de quilombos de Salvaterra, Marajó, Pará, Brasil. Boletim do Museu Paraense Emílio Goeldi Ciências Humanas, Belém, v. 10, n. 2, p.469-488, 2015.

BARRERA-BASSOLS, N.; ZINCK, J.A. Ethnopedology: a worldwide view on the soil knowledge of local people. Geoderma, v.111, p.171-195, 2003. 
BRADY, N. C.; WEIL, R. R. Acidez, Alcalinidade, Aridez e Salinidade do Solo. In. BRADY, N. C.; WEIL, R. R. A Natureza e propriedades dos solos. 3ed. Rio de Janeiro: Bookman, 2013, p.76-97.

CASTRO, F.C.; ARAÚJO, J. F.; SANTOS, A.M. Susceptibility to soil salinization in the quilombola community of Cupira - Santa Maria da Boa Vista - Pernambuco - Brazil. Catena, v.179, p.175-183, 2019.

CHU, S.; ZHANG, D.; WANG, D; ZHI, Y; ZHOU, P. Heterologous expression and biochemical characterization ofassimilatory nitrate and nitrite reductase reveals adaption andpotential of Bacillus megaterium NCT-2 in secondary salinization soil. International Journal of Biological Macromolecules. v. 101, p.1019-1028, 2017.

EMBRAPA - Empresa Brasileira de Pesquisa Agropecuária. Manual de métodos de análises de solo. 2.ed. Rio de Janeiro: EMBRAPA, 2011. 230p.

FILIZOLA, H.F.; GOMES, M.A.F.; SOUZA, M.D. Manual de procedimentos de coleta de amostras em áreas agrícolas para análise da qualidade ambiental: solo, água e sedimentos. EMBRAPA: Jaguariúna, 2006.

GKIOUGKIS, I.; KALLIORAS, A.; PLIAKAS, F.; PECHTELIDIS, A.; DIAMANTIS, V.; DIAMANTIS, I.; ZIOGAS, A.; DAFNIS, I.; Assessment of soil salinization at the eastern Nestos River Delta, N.E. Greece. Catena, v. 128, p. 238-251, 2015.

GONÇALVES, M. C.; MARTINS, J. C.; RAMOS, T. B.; A salinização do solo em Portugal. Causas, extensão e soluções. Revista de Ciências Agrárias, v. 38, p. 574-586, 2015.

GORAYEB, A; MEIRELES, A. J. A; SILVA, E. V. Princípios básicos de Cartografia e Construção de Mapas Sociais. In: GORAYEB, A; MEIRELES, A. J. A; SILVA, E. V (Org.). Cartografia Social e Cidadania: experiências de mapeamento participativo dos territórios de comunidades urbanas e tradicionais. Fortaleza: Expressão Gráfica Editora, 2015. P. 9 -24.

HAMMECKER, C; MAEGHT, J. L.; GRUNBERGER, O.; SILTACHO, S.; SRISRUK, K.; NOBLE, A.; Quantification and modelling of water flow in rain-fed paddy fields in NE Thailand: Evidence of soil salinization under submerged conditions by artesian groundwater. Journal of Hydrology, v. 456 - 457, p. 68-78, 2012.

LIMA, A. C. R.; HOOGMOED, W. B.; BRUSSAARD, L.; ANJOS, F. S. Farmers' assessment of soil quality in rice production systems. NJAS-Wagen. J. Life Sc. NJAS Wageningen Journal of Life Sciences, v.58, p. 31-38, 2011.

NATH, A. J.; LAL, R.; DAS, A. K. Ethnopedology and soil quality of bamboo (Bambusa sp.) based agroforestry system. Science of the Total Environment, v.521-522, p.372-379, 2015.

NEZOMBA, H.; MTAMBANENGWE, F.; TITTONELL, P.; MAPFUMO, P. Practical assessment of soil degradation on smallholder farmers' fields in Zimbabwe: Integrating local knowledge and scientific diagnostic indicators. CATENA, v. 156, p. 216-227, 2017. 
PEDROTTI, A.; CHAGAS, R. M.; RAMOS, V. C.; PRATA, A. P. N.; LUCAS, A. A.T.; SANTOS, P. B.; Causas e consequências do processo de salinização dos solos. Revista Eletrônica em Gestão, Educação e Tecnologia Ambiental Santa Maria, v. 19, n. 2, p. 13081324, 2015.

PENG, J.; JI, W.; MA, Z.; LI, S.; CHEN, S.; ZHOU, L.; SHI, Z.; Predicting total dissolved salts and soluble ion concentrations in agricultural soils using portable visible near-infrared and mid-infrared Spectrometers. Biosystems engineering. v.152, p.94 - 103, 2016.

RIBEIRO, M. R. Origem e classificação dos solos afetados por sais. In: GHEYI, H. R.; DIAS, N. S.; LACERDA, C. F. (Orgs.) Manejo da salinidade na agricultura: estudos básicos e aplicados. Fortaleza: INCTSal, 2010, p.12-19.

SALVATI, L.; FERRARA, C.; The local-scale impact of soil salinization on the socioeconomic context: An exploratory analysis in Italy. Catena, v. 127, p. 312-322, 2015.

SANTOS, D. Cartografia social: O estudo da cartografia social como perspectiva contemporânea da Geografia. Revista InterEspaço, v. 2, n. 6 p. 273-293, 2016.

SHEN, W.; NI, Y.; GAO, N.; BIAN, B.; ZHENG, S.; LIN, X.; CHU, H.; Bacterial community composition is shaped by soil secondary salinization and acidification brought on by high nitrogen fertilization rates. Applied Soil Ecology, v. 108, p. 76-83, 2016.

SILVA, A., O.; A fertirrigação e o processo de salinização de solos em ambiente protegido. Nativa, v. 02, n. 03, p. 180-186, 2014.

TESTEZLAF, R.; Irrigação: métodos, sistemas e aplicações. Campinas: Unicamp/FEAGRI, 2017, 215p.

WAHLHÜTTER, S.; VOGL, C.R.; EBERRHART, H. Soil as a key criteria in the construction of farmers' identities: The example of farming in the Austrian province of Burgenland. Geoderma, v.269, p. 39 - 53, 2016.

\section{Agradecimentos}

Os autores agradecem: a CAPES (Coordenação de Aperfeiçoamento de Pessoal de Nível Superior) pela bolsa de mestrado cedida a primeira autora.

Francelita Coelho Castro

Graduada em Geografia pela Universidade de Pernambuco (UPE) Campus Petrolina, Mestre em Ecologia Humana e Gestão Socioambiental pela Universidade do Estado da Bahia (UNEB) Campus III e atua como professora do ensino superior no Colegiado de Geografia da Universidade de Pernambuco Campus Petrolina.

Endereço: Universidade de Pernambuco. Rodovia BR 203, Km 2 s/n - Vila Eduardo, Petrolina - PE. CEP: 56328-900. Telefone: (87) 3866-6468.

E-mail: francelitacastro@gmail.com 


\section{Antonio Marcos dos Santos}

Doutor em Geografia pela Universidade Federal de Pernambuco (UFPE). Atualmente é Professor Adjunto Nível 1F do curso de Geografia lotado na Universidade de Pernambuco campus Petrolina. Docente do Programa de Pós-Graduação em Ciência e Tecnologia Ambiental para o Semiárido nível mestrado (UPE) e do Programa de Pós-Graduação em Formação de Professores e Práticas Interdisciplinares - nível mestrado (UPE). Coordena o Grupo de Trabalho em Geotecnologia, Monitoramento Ambiental e Ensino (GTMAGEO).

Endereço: Universidade de Pernambuco. Rodovia BR 203, Km 2 s/n - Vila Eduardo, Petrolina - PE. CEP: 56328-900. Telefone:(87) 3866-6468.

E-mail: geo_fisica@yahoo.com.br

\section{Jairton Fraga Araújo}

Doutor em Agronomia pela Universidade Estadual Paulista Júlio de Mesquita Filho (UNESP). Atualmente é professor Titular da Universidade do Estado da Bahia (UNEB). Docente do Programa de Pós-Graduação em Ecologia Humana e Gestão Socioambiental (UNEB) e Coordenador do Doutorado Profissional em Agroecologia e Desenvolvimento Territorial PPGADT no âmbito da UNEB.

Endereço: Universidade do Estado da Bahia, Departamento de Tecnologia e Ciências Sociais (DTCS). Av. Edgard Chastinet, s/n - São Geraldo, Juazeiro - BA. CEP: 48902400. Caixa-postal: 171.

Telefone: (74) 3611-7363 - Ramal: 236 - Fax: (74) 36117363.

E-mail: jairtonfraga@bol.com.br 